\title{
The Application of Micro-media to Adult English Education
}

\author{
Xiaolin Cai \\ Huanghe Science and Technology College \\ Zhengzhou, China
}

\begin{abstract}
The emergence of micro media has brought great changes to people's way of life and new opportunities to the development of adult English education. In particular as micro-blog, WeChat, micro class, Moocc appear, which has gradually changed the teaching mode of adult English education. Because of the uneasy balance between work and study, the uneven content of teaching materials, its teaching effect is widely criticized. Technology is changing the life and the adult English education teaching methods. Through the application of micro media and micro channels of the public platform in adult English education and by creating a movable classroom, adult students can make a effective use of fragmented time, the teaching content are becoming dynamic and personalized, in-classroom can be extended to after-class and a better learning effect can be achieved. At present, domestic universities have realized that opportunities and challenges are brought in educational field by micro media, and the future classroom has initially emerged.
\end{abstract}

Keywords-adult English education; Micro media; WeChat public platform

\section{THE CURRENT SituATION OF ADULT ENGLISH EDUCATION}

As an important teaching form of China's adult higher education, adult English education plays an important role in enhancing adult English proficiency, accelerating economic development, cultivating many English talents, and mastering the English language skills. AS the society is increasingly developing and internationalizing, people become more aware of the importance of mastering the English language tools. Especially in the economically developed areas, for the needs of work and life, men and women regardless of age and occupation, are voluntarily looking for different English learning methods and ways to improve their English level and English literacy.

Since the students of the adult English education are quite different, knowledge reserve of students are also different even in the same classroom. The students who participate in Adult English Education Curriculum may come from all walks of life, workers, teachers, businessmen, farmers and unemployed youth. Some of them have no English basis; some only have English level similar to junior high school; some have not contacted and used English any longer after graduating from high school. They want to improve their English capacity through continuing education though they are at work. They have a common problem which is the big contradiction between work and study and they are busy with family, career and study, therefore they have not enough chunks of time, lack energy, do not form the good habit of studying. These have become the bottleneck to block adult English education from enhancing the teaching quality and learning effect.

In present days, social life is fast-paced, stressful. There are very few people who can concentrate in study in adult English education. Many of them want to find a rapid way to improve their English level and a suitable method to achieve the best learning effect during a short time. Because of different learning motivation, different request for degree of English, different foundation of English learning, and different time length to learn and different learning conditions, it is difficult for the adult English education to choose the same teaching material to achieve same teaching effect. In addition, science and norm, the degree of difficulty of teaching materials need to practice. In conclusion, no form of adult education English cannot continue going the old way of the single form of correspondence education, and should combined with modern science and technology, and develop toward the direction of diversification.

\section{THE ERA BACKGROUND OF MICRO MEDIA}

Today, we have entered a veritable era of micro media. Micro blog, micro channel, micro credit, micro film, micro fiction, micro media, micro advertising, micro payment, micro credit, micro management, small investment, micro life, all of these has been redefined out times in a way of decenterization, dynamics, fragmentation and immediacy which are the new mode of transmission, cultural forms and the economic activities in subtle daily life. The micro era has changed people's traditional information communication, interpersonal communication, cultural expression and social behavior, and has brought new opportunities and challenges for the traditional education and adult English teaching.

In daily life, micro blogging, micro channel, micro, micro film and other forms, are favored by more and more people. These micro media are fast, convenient, large in capacity and rich in content which cover the audio, video, graphics and text, etc. people can make full use of fragmented time to learn them, which brings new opportunity for the rapid development of English education. 


\section{The AdVAntages of Micro Media Used IN THE ADULT ENGLISH EDUCATION}

\section{A. Conveniently and Effectively Using Fragmented Time}

Micro media are convenient and have same rhythm with modern life. In adult education, the micro media represented micro-blog, WeChat, mainly play the role of sharing, transmission and reviewing information. Micro-blog is a relatively open social tool for people to exchange information between the familiar and the strangers, which belongs to the weak link in interpersonal relationships and communicate news and commentary which similar groups are concerned with; WeChat are strong links in the social network mainly to exchange among the acquaintances, including information sharing, review and communication, mainly through the circle of friends to spread message and privacy is strong and communicate quickly by using mass information, graphic video, voice communication means. In the teaching process, we can use micro media advantages, combine the teaching content and teaching arrangement with the class situation, and establish the letter public platform, micro channel and micro channel group, to timely publicize teaching arrangement. Classmates will discuss in advance according to notice and students can use their free time to actively prepare for them so as to improve the teaching effect in the classroom, which directly lead to the students to actively learn in their fragmented time.

\section{B. Spreading Personalized Information and Dynamic Teaching Content}

As the new network applications, micro media are playing an increasingly important role in people's life. In the network due to WeChat, micro-blog and other social media, almost everyone is busy with brushing screen every day for fear of missing the latest information and social relations. Over 300 million people have registered on The WeChat. Basically everyone is unable to stop looking around WeChat before going to bed and waking up in the morning and seeing WeChat has become part of life. Micro media have become the places to acquire and disseminate information; and tools construct online interpersonal relationship. According to their own interests and goals, everyone can select to pay attention to or subscribe the relevant information, which seems like a unique personalized media package; students can subscribe or cancel a variety of newspapers, periodicals at any time. This subscription is very suitable for adult English education and can be applied to the whole education system. Teachers and school organizers can schedule teaching content, curriculum and extracurricular activities according to their members' different age, grade characteristics, and select suitable content to spread news by using different micro letter or @ microblogging. This way, not only has strong pertinence, and Feng often effective, but also timely interaction, changing the previous newspapers, periodicals and other traditional media spread of a single state, so that information can be fully communication, interaction and dialogue. According to the survey, the new teaching style is very popular among 80 's and 90's generation students.

\section{Extending In-class to After-class with the Help of the WeChat Subscription}

In January of 2011, the Tencent Inc developed and promoted the WeChat software. This software is mainly used by the clients of smartphones and computers. In August of 2012, the Tencent Inc developed WeChat public platform subscription service for the enterprise, the media, stars and other groups of users. Since its birth, the WeChat public platform has been greatly respected by the media. The sites, stars, players and ordinary people show QR code. Universities quickly meet the challenges and seize the opportunity. WeChat public platform subscription service opens message broadcasting, brand communication, and enriches the campus culture. This has brought new inspiration to the adult education of English teaching methods. Adult English textbooks are complicated, and textbooks cannot be suitable for all backgrounds of students. In the process of education, by WeChat public platform subscription service, teaching materials, supplementary materials can be selected by teachers and broadcasting to the public students who can participate through the micro channel., the students can learn at any time or any places selective materials personally, so that the classroom content can be extended to extracurricular and learning targeted can be achieved effectively. Students can get reply comment and guidance from the teachers and co- learners. In short, the new technology is of great benefit of adult English education to rapidly improve their English application ability.

\section{Modern Flipped Classroom and Micro Teaching}

Our micro courses sprang up in Foshan City, Guangdong Province in 2010, which immediately called the attention of the national Ministry of Education, and published the micro program accreditation standards. Thus, the micro courses quickly became hot topic in the field of education throughout the country. On December the 28th, South China Normal University and Phoenix TV jointly issued the "Phoenix micro class" among mobile- learning clients. Micro course is extended from the classroom to the society. Just two years later, micro courses have completely and quickly covered from primary schools, middle schools, Universities to the public.

By applied the constructivist method to the online learning or mobile learning, Micro curricula provide practical teaching content; which takes the video as the carrier with a clear theme, brief contents within less than 10 minutes, to show a core problem. Its content is specific, video is compact and it has a low cost to produce. With these advantages, it has become a mutual learning platform for both education workers and learners. They can use mobile technology and equipment, in at any time, at any place, by any way to teach or learn anything. It can mobilize the people of all the senses involved in learning, understand knowledge points. Learning mode of micro lesson within 10 minutes are more in line with the characteristics of adult learning so as to meet the social public learners' needs. 


\section{Building Mobile Classroom By Wechat Public PLATFORM}

According to the report of the thirty-first Cession China Internet development by Chinese Internet Network Information Center (CNNIC) statistics, with the rapid popularization of mobile devices, in 2012 the number of China's mobile phone users was up to 420 million, mobile network has become the mainstream of the network platform. The boundary between the network world and the offline world has become increasingly blurred; network world has become an inseparable part of their life. Everyone lives in the era of micro social background; WeChat has become a way of life. Through the WeChat circle of friends or the number of public concern, people choose to study or share knowledge. Adult education can apply WeChat public account in a unit of class. Teachers are responsible for pushing supplement of teaching material and information.

\section{A. Preconditions to Create a Mobile Classroom}

According to a preliminary investigation, almost all the students have opened Wechat letter, usually by using Smartphone or tablet computers, so that the promotion of the public information platform becomes possible. To push message accurately requires teachers timely understand the specific needs of students on the course content and what information category they want to get according to the teaching contents and classify pushing message. Through the micro channel provided by Wechat service or adding a friend, adding micro channel public platform account, Students can automatically look for navigation menu, or enter a keyword and then they have access to the corresponding function.

\section{B. Using WeChat's Public Platform}

WeChat public platform can be managed by teachers and students as a supplement. They can convert the related course information to the WeChat public platform material information, such as the text, pictures, audio and video. In the WeChat public account background operating system, each message must set the title, cover images and text. The text supports rich texts and links. When editing it, it provides the best summary and the original link graphic message. The adult English teaching material is more various, convenient. Students can also expand reading. Students can give feedback and reply according to the push message. Direct answering from teachers realizes the in-time exchanging of learning. In addition, WeChat public platform is humanistic and can send mass messages; objects can be all users or just particular persons or specified group users. Including, etc. according to the gender or age or the foundation of the students English, classmates can be grouped, and send information to directional users so that it can relieve the students' fear for English learning. By this way can students quickly grasp of learning methods, timely find selfconfidence. Students can also automatically reply, have access to a specific piece of information, meet the students' different needs for knowledge, to enable students to learn knowledge there is a high degree of flexibility.

\section{The Limitations of the Mobile Classroom}

Mobile classroom construction mainly relies on the micro channel public platform, but the micro channel public platform is a new micro media. In some ways there are deficiencies. Public platform every day can only send a message sending. The content of the message need very concise, which requests the teachers choose materials wisely, must strive for perfection. Public platform background management can only be realized on the computer to manage, cannot use mobile devices such as tablet or smartphone to a full range of management.

\section{Long-term Mechanism for the Management of the Mobile Classroom Should Form}

Mobile classroom breaks the traditional limitations in time and space for English learning, and the cyber source is abundant. Establishment of network learning platform on the basis of multimedia network can make learning more efficient and the information more intensive, sharing more resources, communicating more convenient, promoting English teaching more efficient and more conducive to adult self-directed learning. But micro media is a double-edged sword. Information spreads very quickly, so the background of the management and maintenance requires that the teachers have a high sense of responsibility, learn more about student's situation and English level in order to avoid the blindness and to push information and are in strict for screening materials and supplement materials, should have a certain media literacy to avoid bad information.

Teachers can be set up in different teams, and are in charge of different jobs. Due to the adult education teachers are also very busy, also need to collect relevant materials and supplement lectures and expand knowledge of material, which need to spend a lot of energy. Due to the restrictions of teachers' knowledge, organizing and planning ability, and other objective conditions, providing a large number, wide, high-quality resource is an important condition to improve student's learning effect.

According to the characteristics of mobile classroom, schools should form a reward and punishment mechanism, formulate a related management planning, inspire more people to participate in the construction of mobile classroom , make mobile classroom operation more flexible, content more rich, more popular among students, and improve students' learning ability and English level faster.

\section{PROSPECTS}

At present, many domestic colleges and universities have realized that the micro media brings opportunities and challenges to school education, especially in the micro channel, the important role of public platform of teaching management, communication between schools and parents, School of shaping brand culture and propagation, consciously organization related training, to achieve scientific and humanity education and teaching management.

In the practice of in adult English education, it should conform to this trend, initiatively seize the opportunity, use 
advanced science and technology, improve the traditional teaching methods, use micro media, create the independent, open teaching environment, to improve students' autonomous learning ability. Teachers can make full use of the rich Internet sharing resources to enrich background knowledge and teaching contents, and can use it to collect the exercises from network library. Students can choose to download the relevant exercise according to their own actual situation, meet the individual needs and get rid of the various restrictions for the learners in the classroom learning because of their different learning progress, learning level and learning ability.

Bill Gates said: "in the future, it is out of fashion for let a bunch of kids to sit in the classroom and listen to the lecture". Bill Gates claims to reform about higher education, and to promote the higher education into the classroom to hybrid: students can watch star professors at home on the video for homework, and then use class time to participate in the project team and other various interactive activities. He believes that in the future of the classroom, students just watch the video and participate sharing and discussion. The momentum of development in today's Internet multimedia, especially with M0OCs booming, a course of MOOCs can focus thousands of students, even up to 160 thousand students. Courses are interest- oriented and open to those who want to learn, you can come to learn, regardless of nationality. you can register and participate in online learning through just a mailbox and courses can be completed on line and are free from time restrictions. On the mainland, Shanghai Jiao Tong University, the first university joins Yale, MIT, Stanford and other world-class universities together to build the world's largest online courses, and share the world's largest online course network. The prospect of the future classroom has been initially presented.

\section{REFERENCES}

[1] Tao Dong Feng. "Understanding Micro Culture in Micro Era" [J]. China Book Review.2014 (3)

[2] Lu Li. China Reading Newspaper [N].2013 06, 26, 22 Edition

[3] Lu Xin. "Application of Multimedia Technology to Adult English Teaching Practice" [J]. Agriculture and Technology.2007 (12)

[4] Sun Xiaojun. "Micro Media Influence on Education Enformation Dissemination "[J]. China School Education 2013. 